\title{
DEBATIENDO SOBRE DARWIN EN ESPAÑA: ANTIDARWINISMO, TEORÍAS EVOLUCIONISTAS ALTERNATIVAS Y SÍNTESIS MODERNA
}

\author{
Francisco Pelayo \\ Instituto de Historia, CCHS, CSIC*
}

\section{RESUMEN}

En 1909 se celebraron en Valencia y Lorca homenajes a Darwin en el primer centenario del nacimiento. Medio siglo después, los actos y publicaciones de la comunidad científica española con motivo del centenario de la publicación de On the Origin of Species, coincidieron en mostrar una cercanía y aceptación hacia las tesis de la síntesis moderna de la evolución. Durante la primera mitad del siglo $\mathrm{XX}$, en España se desarrollaron controversias entre las posturas darwinistas y antidarwinistas y se difundieron y apoyaron teorías evolucionistas no darwinistas. Aunque pronto se conocieron, comentaron y discutieron los supuestos de la teoría sintética de la evolución, la tendencia mayoritaria en los años cuarenta y cincuenta fue inclinarse por interpretaciones vitalistas y finalistas.

PALABRAS CLAVE: Darwinismo. Antidarwinismo. Teoría sintética de la evolución. Siglo XX.

\section{DEBATING DARWIN IN SPAIN: ANTI-DARWINIAN EVOLUTIONARY THEORIES AND MODERN SYNTHESIS}

\begin{abstract}
Centenary celebrations of Darwin's birth were held in Valencia and Lorca in 1909. Fifty years later, the meetings and the publications of the Spanish scientific community on the occasion of the centenary of the publication of On the Origin of Species showed a proximity and an acceptance towards the theses of the evolutionary modern synthesis. During the first half of the 20th century, there were controversies in Spain between the Darwinian and anti-Darwinian positions. In addition, non-Darwinian evolutionary theories were spread and supported. Though the assumptions of the synthetic theory of evolution were soon known, commented and discussed, the majority trend in the 40 's and 50's was to incline towards finalist and vitalist interpretations of evolution.
\end{abstract}

KEY WORDS: Darwinism. Anti-Darwinian evolution theories. Synthetic theory of evolution. 20th century.

* Trabajo realizado en el marco del Proyecto del MCI: HUM2006-04730 con financiación FEDER. 


\section{INTRODUCCIÓN}

La publicación de On the Origin of Species de Charles Darwin en 1859 tuvo una buena acogida entre sus colegas. La sólida y bien argumentada exposición de sus trabajos permitió en un primer momento a los naturalistas abordar problemas biológicos con una nueva perspectiva, en la que la selección natural era un factor clave para explicar la diversificación de especies. Pero pronto surgieron las limitaciones de la teoría de Darwin, tanto del mecanismo propuesto como de otros factores, como el de la herencia, problemas éste último mal resuelto por el naturalista inglés. Julian Huxley en su Evolution: The modern Synthesis (1942) y posteriormente Peter J. Bowler en The Eclipse of Darwinism (1983), denominaron período de eclipse a los años comprendidos entre finales del siglo XIX y principios del XX, cuando fueron postuladas teorías evolucionistas no darvinistas, como alternativas a la de la selección natural. A partir de los años veinte y durante las dos décadas siguientes, un complejo proceso interno culminó en un consenso entre biólogos experimentales y naturalistas sobre la teoría sintética de la evolución.

El declive y posterior auge del darwinismo a lo largo de las décadas centrales del siglo XX se recibieron y difundieron en España en un marco histórico y científico que cambió radicalmente por la Guerra Civil. Los esfuerzos promovidos desde la Junta para Ampliación de Estudios (JAE) para fomentar la investigación científica y desarrollar nuevas disciplinas científicas como la genética, se vieron afectados tras la contienda provocada por la rebelión militar. Así, la publicación de las obras clave de la teoría sintética de la evolución y la organización de los primeros coloquios internacionales para discutir el consenso de la síntesis moderna, tuvieron lugar en un contexto en el que la guerra, el exilio y la depuración política disgregaron la comunidad científica española. El desmantelamiento de claustros docentes e investigadores universitarios y la creación del CSIC como organismo sustituto de la JAE, se realizó en el marco de una ideología nacional-católica nada favorable para la recepción de la síntesis evolucionista moderna, teoría claramente materialista.

NEODARWINISMO, TEORÍAS EVOLUCIONISTAS NO DARWINISTAS Y SÍNTESIS MODERNA

Desde finales del siglo XIX convivieron las posiciones críticas que incidieron en las debilidades de la teoría de la evolución de Darwin, con una corriente «neodarwinista» surgida de la obra de A. Weismann, que consideraba 
a la selección natural como el proceso esencial de la evolución. En la variada lista de teorías evolucionistas no basadas en la selección natural comenzó incluyéndose la ortogénesis, o fuerza interna que encauzaba el progreso evolutivo en una dirección determinada y el neolamarckismo. La explicación que consideraba a la evolución como un proceso discontinuo apeló a un origen brusco o súbito la formación de nuevas especies. Tomó forma como teoría de la mutación con $\mathrm{H}$. de Vries a comienzos del siglo XX, tras el redescubrimiento de las leyes de Mendel, y contó con la oposición de la Escuela Biométrica, para cuyos integrantes la variación era continua en la mayoría de organismos. Durante los años treinta y cuarenta autores como O.H. Schindewolf, K. Beurlen y R. Goldschmidt defendieron la existencia de saltos súbitos de la evolución. En paralelo, desde comienzos del nuevo siglo continuó la descalificación de la evolución darwinista por parte de sectores cristianos intransigentes, quienes incluso sostuvieron que las ideas de lucha por la existencia y supervivencia del más apto, aplicadas a la sociedad, habían sido el germen de la Primera Guerra Mundial.

Como señaló el paleontólogo norteamericano G.G. Simpson en The Meaning of Evolution (1951) hubo autores para quienes la evolución era inexplicable, así que abandonaron la búsqueda de las causas que la explicaban y sostuvieron teorías vitalistas y finalistas, como la aristogénesis, la nomogénesis, la hologénesis, la conciencia celular, el élan vital, la entelequia, el telefinalismo, etc.

Para aumentar la complejidad de la situación hay que mencionar al michurinismo, defendido en la Unión Soviética por Trofim Lysenko. Para esta interpretación, cuyo nombre hace referencia a Ivan Vladimirovich Michurin un horticultor ruso especialista en hibridación vegetal, la transformación de los organismos tenía lugar bajo la acción del medio. Este acercamiento a concepciones lamarckistas consideraba al darwinismo incompatible con mendelismo y criticaba al neodarwinismo de Weismann. En 1948, el michurinismo fue proclamado en la Unión Soviética doctrina oficial «en materia de genética y de evolución».

Tras los trabajos de R. Fisher, J.B. Haldane y S. Wright, basados en análisis matemáticos y con enfoques estadísticos y poblacionales, se fue configurando la genética de poblaciones, una nueva disciplina que compatibilizaba mendelismo y darwinismo mediante un modelo de explicación que satisfacía a métodos de las tradiciones mendeliana y biométrica. El consenso entre naturalistas de campo y biólogos de laboratorio en torno a la selección natural como causa de la evolución tuvo lugar en las décadas de los años treinta y cuarenta, concretándose durante la Segunda Guerra Mundial. Esta síntesis moderna de la evolución difería de la teoría de Darwin en el rechazo de la herencia de los caracteres adquiridos y en que consideraba que las variaciones sobre las que ac- 
tuaba la selección natural se heredaban según las leyes de Mendel. Las obras claves en la consolidación de la teoría sintética de la evolución y de su aceptación mayoritaria en la biología contemporánea, Genetics and the Origin of Species (1937) de Th. Dobzhansky, Evolution: The Modern Sintesis (1942) de Julian Huxley, Systematics and the Origin of Species (1942) de E. Mayr y Tempo and Mode in Evolution (1944) de G.G. Simpson, se editaron durante en un ambiente nada propicio para la normalidad científica occidental, en medio de la Guerra Civil española, la expansión del fascismo y la Segunda Guerra Mundial.

Tras finalizar la contienda mundial, se constituyó The Society for the Study of Evolution, cuyo órgano de expresión es la revista Evolution, y tuvo lugar en 1947 en la Universidad de Princeton, New Jersey, la conferencia sobre Genética, Paleontología y Evolución, en donde los biólogos norteamericanos de diferentes campos confluyeron en la nueva teoría sintética de la evolución.

\section{DARWIN Y LA EVOLUCIÓN EN ESPAÑA (1900-1939)}

Durante el primer tercio del siglo XX, el debate sobre Darwin y la evolución en la comunidad científica española y en la sociedad, se movió desde un reconocimiento pleno a la obra del naturalista inglés, con los homenajes celebrados en Valencia y Lorca en 1909, centenario de su nacimiento, y la redición y difusión de sus libros, hasta el rechazo y la crítica, especialmente del grupo de jesuitas constituido en torno a Jaume Pujiula, que consideraron al darwinismo una teoría materialista, falsa y caduca que cuestionaba el creacionismo divino. En este último apartado se situaron también posturas como las de Francisco Vidal y Careta, catedrático de Geografía y Geología Dinámica en la Universidad Central, para quien los postulados del darwinismo coincidían con los argumentos que habían justificado la carrera armamentística y la Primera Guerra Mundial. En medio, una gama que iba desde los que aceptaban la importancia de la selección natural como mecanismo de la evolución, como Marcelo Rivas Mateos, catedrático de Mineralogía y Zoología en la Universidad de Barcelona, que reconocía la importancia de Darwin y de su originalidad al proponer el proceso de lucha por la existencia (struggle for life), hasta los que sólo admitían un evolucionismo mitigado o limitado a las especies, pero que no afectaba al origen de la vida ni de la humanidad, que eran obras de la creación de Dios. En paralelo, se difundieron en estas primeras décadas de siglo otras teorías evolucionistas no darwinistas, como la ortogénesis, el neolamarckismo y el mutacionismo, además de teorías vitalistas que se oponían a cualquier explicación que consideraran mecanicista ${ }^{1}$.

Pelayo, F. (2002), Darwinismo y antidarwinismo en España: la extensión y crítica de 
Un ejemplo de la proyección de las teorías evolucionistas fuera del campo científico se encuentra en el pensamiento de José Ortega y Gasset. Benavides ha señalado como, tras una primera etapa con referentes darwinistas y lamarckistas, Ortega adoptó una postura antidarwinista y favorable al vitalismo, promoviendo la traducción de las obras de J. Von Uexküll, biólogo ultravitalista y antidarwinista ${ }^{2}$. Con posterioridad, abandonaría el vitalismo y tantearía orientaciones mutacionistas y saltacionistas, en la línea de R. Goldschmidt, además de las procedentes de paleontólogos alemanes, como H. Klaatsch y Edgar Dacqué. En las páginas de la Revista de Occidente, se recogieron artículos, algunos del secretario de redacción de la revista Fernando Vela, en donde se discutía sobre cuestiones relacionadas con la evolución biológica ${ }^{3}$.

Importante fue en España la influencia del transformismo francés. No sólo se tradujeron obras de autores que se incluyen dentro de la compleja y heterogénea corriente neolamarckista, como J. de Lanessan, E. Rabaud y F. Le Dantec entre otros ${ }^{4}$, sino que pensionados por la JAE, como José Gogorza, Eduardo Boscá, Antonio de Zulueta y Margarita Comas, se dirigieron al Laboratoire d'Evolution des êtres organisés de París que dirigía Maurice Caullery, para adiestrarse en las prácticas de trabajo e investigación teórica en el marco de la biología evolucionista de orientación lamarckista. Así, Gogorza, catedrático de Organografía y Fisiología animal en la Universidad de Madrid, asistió a los cursos orales, trabajos prácticos y de laboratorio impartidos por

las ideas evolucionistas. En PUIG-SAMPER, M.A., RuIz, R. y GALERA, A. (eds.), Evolucionismo y Cultura. Darwinismo en Europa e Iberoamérica, Doce Calles/Editora Regional de Extremadura / UNAM (México), pp. 267-283.

2 Benavides LuCAs, M. (1988), De la ameba al monstruo propicio. Raíces naturalistas del pensamiento de Ortega y Gasset, Madrid, Ediciones de la Universidad Autónoma de Madrid; BLÁZQUEZ PANIAGUA, F. (2004), El evolucionismo en España y la síntesis neodarwinista (1939-1970), Madrid. Tesis Doctoral. Universidad Autónoma de Madrid y BLÁzQuez, F. (2007), Notas sobre el debate evolucionista en España (1900-1936), Revista de Hispanismo Filosófico, 12, pp. 23-44.

3 Véase Vela, F. (1923), El individuo y el medio (Nuevas ideas biológicas), Revista de Occidente, t. I, pp. 95-105; BOLK, L. (1927), La humanización del hombre, Revista de Occidente, t. XVIII, pp. 329-350 y t. XIX, pp. 47-78; VELA. F. (1930), De la mosca al hombre, Revista de Occidente, t. XXVII, pp. 120-132 y DACQUÉ, E. (1934), Esencia y evolución de la vida, Revista de Occidente, t. XLIV, pp. 30-51.

4 Sobre el neolamarckismo francés consúltese el número monográfico de la revista Revue de Synthése, n. 95-96 (juillet-décémbre 1979) y la voz «Néo-lamarckisme» de A. Pauly en TORT, P. (dir.) (1996), Dictionaire du darwinisme et de l'evolution. También puede verse el artículo de CONRY, Y. (1993), Comment a-t-on pu être néolamarckien en France (18431930)?, Nuncius, VIII (2), pp. 487-520. 
Caullery, Charles Pérez, Émile Guyenot y E. Rabaud ${ }^{5}$. M. Comas publicó a su regreso a España algunos de sus trabajos experimentales en París, informó de la reunión sobre evolución organizada en París por el Centre Internationale de Synthèse, en la que participaron Guyenot y Caullery, y reseñó el libro de éste último, Le problème de l'Évolution (1931) . Por su parte, Boscá, catedrático de Historia natural en la Universidad de Valencia, entró en contacto, en París, con Caullery, cuyo laboratorio de embriología era un centro de investigaciones sobre el evolucionismo, centrado en el estudio de la influencia del medio sobre los organismos. Boscá asistió en la Sorbona a una conferencia de Caullery en la que éste disertó sobre los resultados obtenidos con un enfoque evolucionista en paleontología y embriología ${ }^{7}$.

De especial relevancia para la consolidación del evolucionismo en España en las primeras décadas del siglo XX fue la línea de investigación desarrollada en genética por el grupo vinculado al Laboratorio de Biología del Museo Nacional de Ciencias Naturales, dirigido por Antonio de Zulueta. En el museo, Zulueta desarrolló en el Laboratorio de Biología un programa de investigación en genética que contribuyó a la consolidación del evolucionismo en España, gracias a la introducción de los conceptos fundamentales sobre la herencia mendeliana y la teoría cromosómico-mendeliana. Zulueta mantuvo contactos R.C. Punnet y T.H. Morgan, en cuyo laboratorio conoció a T. Dobzhansky. Una colaboradora de Zulueta fue Kate Päriser, alumna de R. Goldschmidt. Éste último medió ante la Rockefeller Foundation para que financiara en Madrid la construcción de un laboratorio de investigación genética donde se pudiesen formar jóvenes científicos ${ }^{8}$.

Zulueta realizó una importante labor divulgativa del evolucionismo en los años veinte. Tradujo El origen de las especies por medio de la Selección Na-

5 Gogorza GonzÁlez, J. (1911), Estudios de Anatomía Comparada y de Embriología, Anales de la Junta para Ampliación de Estudios, 5 (Memoria 6), pp. 249-293

6 Comas, M. (1930), Conferencias y Reseñas Científicas de la Real Sociedad Española de Historia Natural, V (1930), pp. 37-38 y VII (1932), pp. 154-156.

7 Pelayo, F. (2007), La evolución humana y su difusión en España en el marco de la JAE (1907-1939), Asclepio, LIX (2), pp. 137-162.

8 Para el caso de la Genética véase PINAR, Susana (1999), La introducción de la Genética en España durante el primer tercio del siglo XX, Llull, 22 (44), pp. 453-473; PINAR, S. (2002), The Emergence of Modern Genetics in Spain and the Effects of the Spanish Civil War (1936-1939) on Its Development, Journal of the History of Biology, 35, pp. 111-148 y PINAR, S. (2003), Antonio de Zulueta y los orígenes de la Genética en España. En CANDELA, M. (ed.), Los orígenes de la genética en España, Madrid, Sociedad Estatal de Conmemoraciones Culturales, pp. 165-201. 
tural, de Charles Darwin (Madrid, Espasa Calpe, 1921), La teoría de la evolución y las pruebas en que se funda, de William B. Scott (Madrid, Espasa Calpe, 1920), Evolución y Mendelismo (Crítica de la teoría de la evolución), de Thomas H. Morgan (Madrid, Espasa Calpe, 1921). Scott, profesor de la Universidad de Princeton, comenzó siendo crítico con el neodarwinismo de Weissmann y con las variaciones arbitrarias y discontinuas de W. Bateson, al tiempo que adoptó posiciones neolamarckistas aunque no extremas. Posteriormente, apoyó el hecho de la evolución pero sin definir cuál era su causa ${ }^{9}$.

Estas traducciones de Zulueta fueron criticadas en la revista de los jesuitas Razón y Fe por Miguel Gutiérrez, profesor en la Universidad Pontificia de Comillas. Gutiérrez consideraba que la difusión en España de las obras de Darwin, Scott y Morgan era pura propaganda evolucionista que intentaba evitar el descrédito científico en el que, en su opinión, había caído la teoría. Al referirse al libro de Darwin, Gutiérrez decía que era una obra anticuada y sus ideas pasadas de moda. Entre los antidarwinistas franceses y alemanes que citaba, Gutiérrez se extendía con Dacqué, profesor de paleontología de la Universidad de Munich, un representante del movimiento de la morfología idealista que también había atraído la atención de Ortega y Gasset. Para Dacqué, de las tres series evolutivas, la de adaptación, la de gradación y la de ascendientes o antepasados, sólo ésta última podía proporcionar pruebas de las genealogías entre los organismos, pero no se conocía ni un solo ejemplo de ella ni entre invertebrados ni entre vertebrados ${ }^{10}$.

Una perspectiva de la situación en que se encontraba el evolucionismo a finales de los años veinte fue expuesta por Zulueta, en su artículo «Estado actual de la teoría de la evolución». En este trabajo discutió sobre la herencia de los caracteres adquiridos, la posible ineficacia de la selección, la hibridación, la ortogénesis, las mutaciones, etc. Zulueta comenzaba distinguiendo que la evolución era un hecho real aceptado por los científicos, quienes debatían el modo en que se había efectuado la transformación de unas especies en otras y las causas que habían provocado tales modificaciones. Además de las pruebas clásicas de la teoría de la evolución, para lo cual remitía a su traducción de la obra de W.B. Scott, Zulueta señalaba las que se basaban en las reacciones sanguíneas entre animales afines y la hibridación, aunque ésta última

9 SimPSON (1948), Biographical Memoir of William Berryman Scott 1858-1947, National Academy of Sciences, vol. XXV (Seventh Memoir), pp. 173-203.

10 GutiÉRREZ, M. (1922), La actual propaganda evolucionista en España y los recientes impugnadores del evolucionismo, Razón y Fé, t. 63, pp. 482-494 y GuTIÉRREZ, M. (1923), Algo sobre Carlos Darwin, Razón y Fé, t. 66, pp. 209-223. 
sólo podía ser uno de los factores de la evolución, pero no su causa. Exponía que la mayoría de los biólogos daban gran importancia a las pequeñas variaciones, buscas y hereditarias denominadas mutaciones. La selección natural se ejercería sobre estas pequeñas mutaciones dando lugar a las variaciones necesarias para que tuviera efectos. Pero añadía que el problema era que las mutaciones conocidas no parecían ser beneficiosas, sino más bien perjudiciales. Además, parecía imposible que muchas de las complejidades orgánicas hubieran podido originarse por selección de mutaciones ocasionales, por muy frecuentes que fuesen ${ }^{11}$.

A la introducción de la Genética en España, contribuyeron, asimismo, dos profesores de la Universidad de Murcia, formados en el Museo de Madrid, José Fernández Nonídez ${ }^{12}$ y José Loustau Gómez de la Membrillera, doctores en Ciencias Naturales en la Universidad Central. Este último, próximo a la derecha liberal republicana, llevó a cabo en las década de los años veinte y treinta, una importante labor de difusión y de apoyo al darwinismo a través de sus libros de texto ${ }^{13}$, cursillos universitarios y conferencias de extensión cultural ${ }^{14}$.

En su trabajo «La ofensiva contra el darwinismo», Loustau rechazaba las críticas que Darwin y el evolucionismo recibían por parte de autores que pretendían, no refutar una teoría científica, sino socavar las ideas de libertad individual y social derivadas de las doctrinas transformistas. Aunque eran de sobra conocidas las pruebas clásicas de la evolución, aún subsistía la concepción creacionista de las especies, un concepto dogmático impuesto por las creencias religiosas. Para él existía una cruzada contra el darwinismo y, por extensión que sólo la ignorancia podía justificar, contra el transformismo en general. Esta guerra declarada contra el darwinismo coincidía con el resurgir de un vitalismo de múltiples y confusas modalidades basado sólo en la ignorancia y con sólo el argumento del resurgimiento de dogmas que negaban los

11 Zulueta, A. (1928), Estado actual de a teoría de la evolución, Conferencia y Reseñas Científicas de la Real Sociedad Española de Historia Natural, t. III, pp. 111-119. Se publicó originalmente en el número 78 de la Revista de Pedagogía de junio de 1928.

12 PINAR, S. (1999), La recepción de la teoría cromosómico-mendeliana en España: la contribución de José Fernández Nonídez, Asclepio, 51 (1), pp. 27-54 e PINAR, S. (2003), José Fernández Nonídez, introductor en España de la teoría cromosómica de la herencia. En CANDELA, M. (ed.), Los orígenes de la genética en España, Madrid, Sociedad Estatal de Conmemoraciones Culturales, pp. 235-257.

13 Loustau Gómez de la Membrillera, J. (1925, $2^{a}$ edición, 1935), Principios de Biología General y Genética, Murcia.

14 Valenciano Gaya, L. (1979), El rector Loustau y la Universidad de Murcia, Murcia, Academia Alfonso X el Sabio. 
principios liberales del desenvolvimiento de la vida humana. Para Lostau, el vitalismo de su época era de la misma naturaleza que el animismo de los hombres primitivos. Lostau decía que Darwin había cuestionado la concepción antropocéntrica, al postular la idea de la evolución frente a la del fijismo de las especies, en donde la humanidad, cuya especie derivaba de antropoides superiores, formaba parte del gran conjunto de organismos que habitaban la Tierra. Terminaba Lostau reflexionando sobre la forma pasional en que se exponían los diferentes puntos de vista, muchas veces debido a rivalidades entre científicos y, otras, a sentimientos nacionalistas. Estas controversias provocaban perturbaciones entre los no especialistas en problemas biológicos y esto era aprovechado fuera del ámbito científico para socavar los fundamentes del conocimiento ${ }^{15}$.

Al mismo tiempo, desde finales de los años veinte se difundieron en España obras de científicos que iban a participar en el diseño de la teoría sintética de la evolución, como Julian Huxley y J.B.S. Haldane. Así, en 1929 Ignacio López Valencia tradujo la Biología Animal (Madrid, Manuel Aguilar Editor) redactada por estos dos autores. A lo largo de sus cuatrocientas páginas exponen ampliamente las pruebas para sostener la realidad de la teoría de la evolución. En los años treinta el mismo traductor se encargó de verter al castellano La ciencia de la vida, de J. Huxley, H.G. Wells y G.P. Wells, publicada originalmente en fascículos bimensuales. En los dos volúmenes, que ocupan en conjunto más de mil páginas, los autores hacen un repaso exhaustivo del estado presente del conocimiento sobre biología evolucionista.

Haldane mantuvo una estrecha relación con España debido a su activismo político, viajando hasta nuestro país en 1933 para apoyar al PSOE y al PCE. Posteriormente volvería ya en plena guerra en 1937, participando, aunque de manera pequeña como él afirmaba, en la defensa de Madrid. Visitó el Museo de Ciencias Naturales, donde encontró a Zulueta y su discípulo Fernando Galán investigando en cuestiones de genética en medio de los bombardeos franquistas. Esta escena fue publicada en la revista Nature en 1937, en una nota enviada por el propio Haldane. Durante su estancia en Madrid ese año, Haldane publicó el artículo «A Dialectical Account of Evolution» en la revista Science \& Society (1937). Tras disculparse de que las bombas de Franco le habían impedido consultar trabajos de referencia, señalaba que el primer inglés que había muerto por defender la democracia en España había sido John Conford, biznieto de Charles Darwin, un poeta, militante comunista y miem-

15 Loustau Gómez de la Membrillera, J. (1930), La ofensiva contra el darwinismo, Anales de la Universidad de Murcia, 1, pp. 21-48. 
bro de las Brigadas Internacionales, caído en el frente de Lopera (Jaén) ${ }^{16}$.

Ejemplo de activismo político puede hallarse en Enrique Rioja ${ }^{17}$, especialista en invertebrados en el Museo Nacional de Ciencias Naturales. Comprometido con el gobierno de la República y exiliado a México tras el triunfo del franquismo, publicó en 1937 el artículo «Darwinismo y marxismo» ${ }^{18}$.

Lluis Solé Sabarís, profesor auxiliar de Geología en la Universidad de Barcelona ${ }^{19}$, contribuyó al debate darwinista durante el período bélico español. Abordó el problema de la evolución de las especies desde la paleontología, afirmando que los biólogos aceptaban como indiscutible el hecho de la evolución, pero existían diversos criterios a la hora de explicar cuál era la causa eficiente de la transformación. Comentaba como había grupos biológicos cuya evolución no se realizaba uniformemente a través del tiempo sino mediante «saltos» y, mientras algunas especies y grupos no sufrían transformación alguna, otros lo hacían rápidamente, lo que en biología se denominaba mutación. Pero aclaraba más adelante que la diferencia entre genotipo y fenotipo marcaba en paleontología el ritmo del cambio, ya que la evolución genotípica se realizaba a través de un proceso lento y gradual, mientras que la fenotípica, que era la que se observaba en las formas fósiles, se realizaba a saltos y de una manera discontinua. Terminaba señalando Solé que la paleontología demostraba que podían distinguirse tres tipos de series evolutivas, las filogenéticos o genealógicas, la de adaptación y las ortogéneticas, series que coincidían con las que Dacqué había denominado de ascendientes o antepasados, de adaptación y de gradación ${ }^{20}$.

Tras la derrota de la República en 1939 tuvo lugar el exilio de intelectuales y científicos, el desmantelamiento y nueva formación de los centros universi$\operatorname{tarios}^{21}$ y la creación de un nuevo organismo estatal de investigación científi-

16 Haldane, J.B.S. (1937), A Dialectical Account of Evolution, Science \& Society, 1 (4), pp. 473-486.

17 CASO, E. (1990), Homenaje a Don Enrique Rioja Lo Bianco en el cincuentenario de su llegada a México, México.

18 Rioja, E. (1937), Darwinismo y Marxismo, Nueva Cultura. Información crítica y orientación intelectual, Valencia, p. 321. Véase Pelayo (2002), pp. 282-283.

19 Riba Arderio, O. (1990), Lluis Solé Sabarís (1908-1985). Maestro de geólogos y geógrafos, Boletín de la Real Sociedad Española de Historia Natural (Actas), 86, pp. 25-59.

20 SolÉ SABARís, L. (1938), Introducción a la Geología, Barcelona, Editorial Apolo, especialmente pp. 253-264.

21 Otero Carvajal, L.E. (dir.) et al. (2006), La destrucción de la ciencia en España. Depuración universitaria en el franquismo, Madrid, Universidad Complutense de Madrid; Claret Miranda, J. (2006), El atroz desmoche. La destrucción de la Universidad española por el franquismo, 1936-1945, Barcelona, Crítica. 
ca, el CSIC. Entre los exiliados se encontró el núcleo dirigente del Museo de Ciencias Naturales de Madrid, Bolívar y su entorno, entre ellos el paleontólogo José Royo Gómez y Rioja. Respecto a los que se quedaron, algunos fueron depurados e inhabilitados para ejercer cargos, como Zulueta, acusado entre otras cosas de haber estado afiliado a Izquierda Republicana. Tras prohibirle pisar el Laboratorio de Biología y retenerle su sueldo, Zulueta pudo volver al Museo de Ciencias Naturales integrado en el recién creado CSIC, como jefe de la sección de Biología Experimental en el nuevo Instituto José de Acosta de Ciencias Naturales y profesor agregado en el Centro de Investigaciones Zoológicas. Pero sin medios ni ánimos, su trabajo científico no fue el mismo que antes de la guerra. El caso de la genética es un ejemplo de como la Guerra Civil, y el posterior aislamiento internacional, no facilitó el desarrollo normal de líneas de investigación experimental y de intercambio científico que, de continuar, hubiera permitido una más fácil introducción de la teoría sintética de la evolución en España tras la Segunda Guerra Mundial.

\section{LA EVOLUCIÓN EN ESPAÑA A COMIENZOS DEL FRANQUISMO}

Mientras tenían lugar reuniones científicas como la de Princeton, donde se abordaba y discutía la nueva síntesis evolucionista moderna, en España la política nacional-católica del régimen de Franco estableció el escenario ideológico en el que los científicos que se quedaron en España, por convicción o por necesidad, tuvieron que trabajar y publicar. Esta adaptación a las circunstancias políticas significó que una cuestión científica de elevado contenido teórico, como la teoría de la evolución, se defendiera desde las instituciones oficiales en un marco de armonía entre la ciencia y la religión católica. En este sentido, el Consejo Superior de Investigaciones Científicas, organismo que asumió las competencias de la extinta JAE, tenía como objetivo principal la recuperación de un pensamiento hispánico confesional, que el ministro de Educación Nacional, José Ibáñez Martín lo resumiría en el lema: «Por la ciencia hacia Dios» ${ }^{22}$.

La primera publicación que abordó el tema de la evolución en España en la posguerra fue una memoria antidarwinista, en una línea del evolucionismo teísta, publicada en 1941 en la revista de la Real Academia de Ciencias Exac-

22 Claret Miranda (2006), p. 58. Remite al discurso de inaugural de Ibáñez Martín en la Facultad de Ciencias de Valencia de 1944, titulado «Renacimiento científico en la investigación y en la docencia». 
tas, Físicas y Naturales de Madrid. Su autor fue un ingeniero de minas, especialista en tectónica, Eugenio Cueto y Rui-Díaz ${ }^{23}$. Criticaba a Darwin por su exagerada inclinación a teorizar, que en su opinión era la raíz de las debilidades de su doctrina. Negaba la capacidad de los mecanismos propuestos por el naturalista inglés, es decir, la selección natural y la lucha por la existencia, y afirmaba que otros dos conceptos capitales, como eran la herencia de transmisión de los caracteres adquiridos y la variabilidad o capacidad de adaptación al medio, no contribuían a explicar las objeciones que se planteaban a su teoría. Terminaba el primer apartado de la memoria haciendo un repaso crítico por las teorías evolucionistas alternativas. En la segunda parte, tras plantear las posiciones mecanicistas, finalistas y vitalistas, expuso su tesis de la evolución orgánica biogenética, según la cual en la naturaleza, además de los fenómenos físicos y químicos, actúa también un agente natural o fuerza biogenética, cuya actividad creadora se extendía por toda la superficie del globo terráqueo. De manera que el origen de la vida había comenzado a manifestarse en múltiples lugares y su poder modificador había provocado una serie de transformaciones encaminadas a perfeccionar y diversificar los organismos, para adaptarlos a las circunstancias más variadas. Las modificaciones que en el curso de la evolución experimentaban los organismos abarcaban a toda su estructura y afectaban a la totalidad de cada especie. El factor determinante de la evolución era, por tanto, la actividad biogenética. Las condiciones de vida y las relaciones orgánicas, como la lucha por la existencia, los hábitos, etc., eran elementos secundarios en las transformaciones de los organismos, mientras que la herencia y la adaptación eran resultados de la actividad de los factores de naturaleza biogenética. En esta explicación, decía Cueto, el azar estaba totalmente excluido ${ }^{24}$.

Al año siguiente, 1942, la revista Escorial, editada por la Delegación de Prensa y Propaganda de la Falange (FET de la JONS), publicó la traducción de un artículo muy crítico con la idea de evolución. Su autor, el profesor de botánica de la Universidad de Lund, Nils Heribert-Nilsson, afirmaba que la evolución de Darwin se había mostrado sin vida y, lo que era peor, como una ficción, y concluía diciendo que «la teoría de la evolución, en lo que se refiere al origen de las especies, no puede corroborarse por medio de una investigación experimental» ${ }^{25}$.

23 Véase necrológica El Excmo. Sr. D. Eugenio Cueto y Rui-Díaz, Estudios Geológicos, t. XII, 1956, pp. 5-6, Lám. I.

24 Cueto y Rui-DíAz, E. (1941), La evolución orgánica biogenética, Revista de la Real Academia de Ciencias Exactas, Físicas y Naturales de Madrid, t. XXXV, pp. 415-441 y 515-549.

25 Heribert-NiLSSSON, N. (1942), La idea de la evolución y la biología moderna, Escorial. Revista de Cultura y Letras, t. VI, pp. 193-209. Cita del texto, página 207. 
Otro autor en que se apoyaron los antidarwinistas españoles fue Oskar Kuhn. Su trabajo crítico con la teoría de la evolución, «Die Deszendenztheorie. Eine Kritische Übersicht», publicado en 1943 en la revista Zeitschrift fur Katholische Theologie, fue ampliamente comentado ten la revista Verdad y Vida por el franciscano Fernando Alcina, en su artículo «La caída de la teoría de la descendencia. Ensayo crítico de Oskar Kuhn» ${ }^{26}$.

En el nuevo marco ideológico de los primeros años de la posguerra se mantuvo la línea que siempre habían defendido los sectores más conservadores y religiosos de vincular el evolucionismo al materialismo, especialmente en relación al origen del género humano. Así, desde finales de la década de los cuarenta y durante los años cincuenta, se incidirá, desde una perspectiva teológica y filosófica, en el relato bíblico de la creación, al tiempo que se contemplará de manera crítica la teoría de la evolución, sobre todo aplicada al género humano. Diversos artículos de esta tendencia se publicarán en este período en revistas como Razón y Fé, Ibérica, Pensamiento, Miscelánea Comillas, Verdad y Vida, La Ciencia Tomista, Estudios Eclesiásticos, Ilustración del Clero, editadas por órdenes religiosas (jesuitas, franciscanos, dominicos y claretianos); en Ecclesia, de Acción Católica Española; en Hechos y Dichos, del Centro Loyola de Estudios y Comunicación Social; en la Revista Española de Teología y Estudios Bíblicos, del Patronato «Raimundo Lulio» del CSIC; en Cultura Bíblica, de la Asociación Fomento de Estudios Bíblicos y en Espíritu, del Instituto Filosófico de Balmesiana.

Los jesuitas, como en las décadas anteriores, continuaron siendo productivos en cuanto a trabajos críticos relacionados con la evolución. Aparte del persistente Pujiula, se puede mencionar a Alejandro Roldán, Jaime Echarri y Jesús Muñoz. El más volcado en el problema de la evolución, especialmente en su vertiente de paleontología humana, desde 1946 hasta su muerte en 1954, fue Valeriano Andérez. Impartió el seminario «Problemas Biológicos y Antropológico» en la Facultad de Filosofía de la Universidad de Comillas. Trabajó con Pujiula en el Instituto Biológico de Sarriá en problemas de genética pero decidió centrarse en cuestiones de evolución y paleontología humana ${ }^{27}$.

Tras publicar el artículo «Concepto de caracteres adquiridos»" Andérez abordó en 1947, el mismo año en que habían tenido lugar el congreso de

26 Alcina, F. (1946), La caída de la teoría de la descendencia. Ensayo crítico de Oskar Kuhn, Verdad y Vida, año IV, n.s., 13-16, pp. 109-137.

27 Una biografía y bibliografía de Andérez pude consultarse en su necrológica: In memoriam, Pensamiento, 11 (1955), pp. 380-382.

28 AndÉrez, V. (1946), Concepto de caracteres biológicamente adquiridos, Pensamiento, 2 (8), pp. 395-414. 
Princeton, cuál era en su opinión el estado de la cuestión de la teoría de la evolución, preguntándose si estaba en crisis ${ }^{29}$. Citaba las opiniones favorables y en contra de la teoría transformista. Entre los mayores críticos citaba a P. Lemoine, A. Fleischman, O. Kuhn, L. Bounoure, al que denominaba «biofijista», Heribert-Nilsson, Lecomte de Noüy, para quien la fe en la evolución era más de origen intuitivo o metafísico que científico, y entre los españoles, además de a Pujiula, al agustino Toribio de Castro y al por entonces profesor de geología de la Universidad de Granada, Bermudo Meléndez, para quienes el transformismo no pasaba de ser una hipótesis. Los partidarios del transformismo eran más numerosos, aunque discrepaban en cuanto a los mecanismos de la evolución. Además de la mayoría de los biólogos franceses, L. Cuenot, M. Boule, J. Piveteau, J. Rostand, M. Caullery, E. Guyenot, etc., incluyendo a autores católicos como T. de Chardin y C. Begouen, Andérez citaba a J. Huxley, J.B.S. Haldane, y su obra evolucionista escrita en colaboración, traducida al español en 1929, así como a R. Goldschmidt, de cuyo libro sobre las bases materiales de la evolución había una edición en castellano de 1943. De España mencionaba a Solé Sabarís, Loustau Gómez de la Membrillera y J. Fuset Tubiá. Éste último, fue catedrático de Biología General y Zoología de Vertebrados en la Universidad de Barcelona hasta 1937, en que, a pesar de sus ideas políticas republicanas, fue jubilado en plena Guerra Civil por refugiarse en Mallorca, zona franquista. Acabada la contienda no pudo volver a la Universidad, siendo depurado y jubilado por las autoridades franquistas ${ }^{30}$. De él decía Andérez que expresaba su adhesión al transformismo sin plena objetividad e imparcialidad científica, en su Manual de Zoología (1944), que estaba impregnado de evolucionismo primitivo, tan arrogante y seguro de sí como despectivo e incomprensivo del fijismo por razones no del todo científicas. Tras volver a citar a Meléndez, al que atribuye una actitud auténticamente científica, Andérez concluye afirmando que los biólogos eran en su inmensa mayoría transformistas moderados. Una minoría de biólogos eran transformistas vitalistas y, aunque pocos, los que se declaraban cerradamente antitransformistas eran autorizados y se presentaban muy decididos. De lo anterior se desprendía que respecto al transformismo, en general y según los biólogos, no había crisis subjetiva en sentido estricto, pero sí en sentido amplio. En cuanto al transformismo clásico, absoluto, mecanicista, no sólo estaba en crisis sino que había sido abandonado casi univer-

29 ANDÉREZ, V. (1947), ¿La opinión transformista en crisis?, Razón y Fé, 136, pp. 207-228.

30 CAmós CABEceran, A. (2006), Josep Fuste Tubià (1871-1952), defensor de l'evolucionisme als anys més negres de la postguerra. En Actes de la VIII Trobada d'Història de la Ciencia i de la Tècnica, Barcelona, SCHCT, pp. 509-515. 
salmente. Terminaba con una nota de Teilhard de Chardin publicada en la revista Etudes, en la que comentaba una reunión científica que había tenido lugar en París en abril de 1947. Según la interpretación de Andérez, en el simposium los participantes habían coincidido en el hecho de la evolución, aunque discreparon acerca del modo en que se verificaba, que había oscilado del mecanicismo casualista al vitalismo finalista.

El encuentro científico a que hacía referencia Andérez se había organizado bajo los auspicios de la Fundación Rockefeller y el Centre National de la Recherche Scientifique (CNRS). Fue un Coloquio Internacional de Paleontología que iba a tener bastante repercusión en España. El objetivo del encuentro fue confrontar los puntos de vista de paleontólogos y genéticos con relación a las teorías de la evolución. Los científicos franceses, por una serie de factores, entre ellos la influencia de las ideas de Lamarck, desde un principio se habían mostrado reticentes al darwinismo, aunque aceptaban el hecho de la evolución. A este encuentro internacional asistieron paleontólogos y expertos en genética, como los franceses J. Piveteau, H. Vallois, M. Caullery, C. Arambourg, L. Cuenot, P.-P. Grassé, Teilhard de Chardin, J. Viret, etc., Simpson, los británicos J.B.S. Haldane, D.M.S. Watson, T.S. Westoll, y el sueco E.A. Stensiö entre otros. Los paleontólogos asistentes, prácticamente todos los franceses además de Simpson, tendrían una estrecha relación científica con sus colegas españoles de la posguerra, puesto que muchas de las cuestiones discutidas en este encuentro internacional, como el tema de la ortogénesis, interesaban mucho a los paleontólogos españoles.

En 1949 Andérez publicó un artículo sobre la imposición política en la Unión Soviética, por parte de Stalin y Trofim Lyssenko, del michurinismo como teoría científica. Andérez aprovechaba para criticar no sólo el materialismo y ateismo de los comunistas soviéticos, sino también las explicaciones evolucionistas tanto darwinistas como lamarkistas. Andérez señalaba que ningún sistema mecanicista y «casualista» podía explicar el origen y la evolución de los organismos. Tras comentar las insuficiencias del mutacionismo mendeliano, y hacer referencia a la nueva tendencia evolucionista que rescataba la teoría de Darwin e incorporaba los datos de la Genética, decía que era preciso recurrir a un principio vital «suprafísicoquímico» que actuaba con una finalidad y que había sido «producido en los comienzos del reino orgánico, por una intervención especial de la Causa Creadora Inteligente sobre la materia orgánica» ${ }^{31}$.

31 Andérez, V. (1949), Biología soviética. El «Mitschurinismo», Razón y Fé, 140, pp. 380-397. 
La nueva genética rusa de orientación neolamarckista también fue comentada por un compañero de orden de Andérez, Alejandro Roldán. Profesor de antropología y psicología en la Facultad de Filosofía de la Compañía de Jesús en San Cugat del Vallés, Roldán publicó una interesante obra titulada Evolución. El problema de la evolución y de la antropogénesis (1950). En ella intentaba tratar el evolucionismo de la manera más completa posible. En los siete capítulos que ocupaban las 240 páginas del libro, abordaba el origen histórico de la teoría evolucionista, el planteamiento del problema desde los aspectos teológico, filosófico y científico, las pruebas de la evolución menor o microevolución y los hechos contra la evolución mayor o macroevolución, para terminar con la evolución regresiva. Desde un punto de vista científico consideraba tres opiniones sobre el origen de las especies, el fijismo absoluto, el fijismo moderado o específico o microevolución y el evolucionismo absoluto o macroevolución, que comparaba en un esquema con otras tres desde la perspectiva filosófica, el creacionismo no-evolucionista, el evolucionismo creacionista y el evolucionismo no-creacionista, respectivamente. En las conclusiones Roldán rechaza el evolucionismo, dedicando dos capítulos a exponer argumentos anatómicos, genéticos, embriológicos y paleontológicos que, en su opinión, que se oponen a lo que llama evolución mayor o macroevolución. Pero matiza que la prudencia exige una actitud psicológica expectante cara al futuro y que su actitud contraria no era absolutamente irrevocable, ya que podrían aparecer nuevos datos que obligaran a cambiar de posición ${ }^{32}$.

\section{LAS PRIMERAS REFERENCIAS EN ESPAÑA DE LA TEORÍA SINTÉTICA DE LA EVO- LUCIÓN}

Entre 1943 y 1946 estuvieron disponibles versiones españolas de las obras de Goldschmidt ${ }^{33}$, Morgan ${ }^{34}$ y Huxley ${ }^{35}$, publicadas en Buenos Aires, las dos primeras por la editorial Espasa-Calpe y la tercera por Losada. Además, en 1945 la editorial Lauro de Barcelona publicó en el tomo IV, «Fundamentos de

32 RoldÁn, A. (1950), Evolución. El problema de la evolución y de la antropogénesis, Barcelona, Editorial Atlántida, pp. 222-227.

33 Goldschmidt, R.B. (1943), La base material de la evolución, Buenos Aires, EspasaCalpe.

34 Morgan, T.H. (1943), La base cientifica de la evolución, Buenos Aires, EspasaCalpe.

35 HuXLey, J. (1946), La evolución, sintesis moderna, Buenos Aires, Losada. 
la ciencia moderna», de la colección La Aventura del Hombre, un trabajo del genético mendeliano R.C. Punnett, titulado «Cuarenta años de teoría evolucionista ${ }^{36}$. En 1947, el editor José Janés de Barcelona, publicó el libro Mundos Posibles de Haldane, que incluía el capítulo «El darwinismo hoy» ${ }^{37}$.

La primera referencia en España de una de las obras clave del consenso sobre la teoría sintética de la evolución data de mediados de la década de los años cuarenta $^{38}$. En el Boletín de la Universidad de Granada, Bermudo Meléndez, en ese momento catedrático de geología de esa universidad, publicó en 1945 una reseña de la obra Tempo and Mode in Evolution (1944) de Simpson. El nombre de éste último por un error de imprenta aparece como Sintson ${ }^{39}$.

Meléndez se había licenciado en Ciencias Naturales en 1936 en la Universidad Central. A partir de 1939 fue auxiliar de la cátedra de ciencias geológicas y becario en el Museo de Ciencias Naturales, en el Instituto José de Acosta perteneciente al recién creado CSIC. Posteriormente fue colaborador, y años después jefe, en la sección de paleontología del Instituto Lucas Mallada del CSIC, catedrático de Geología en la Universidad de Granada entre 1944 y 1949 y de Paleontología y Geología histórica en la Universidad de Madrid.

En su reseña Meléndez señalaba que Simpson pretendía en su obra conciliar el modo de ver la evolución de biólogos y paleontólogos, cuyos puntos de vista habían sido objeto de duras críticas por el campo contrario. Como especialista en paleontología de vertebrados, Simpson establecía sus estudios basándose en las series filogenéticos conocidas, especialmente en la genealogía de los équidos en Norteamérica, demostrando como se formaban en el tiempo la especies y los individuos. Profundizaba Simpson en el modo en que tenía lugar la evolución, que explicaba mediante la variabilidad de las especies que era la causa principal de que tuvieran lugar los cambios-, el carácter diverso de las modificaciones anatómicas, la duración de las generaciones, el

36 PunnetT, R.C. (1945), Cuarenta años de teoría evolucionista. En: CornFord, F.M. et al., Fundamentos de la ciencia moderna, vol. IV de la colección La Aventura del Hombre, Barcelona, Lauro, pp. 151-173.

37 Haldane, J.B.S. (1947), El darwinismo, hoy. En Mundos posibles, Barcelona, José Janés, pp. 31-45.

38 Sobre la teoría sintética en España pueden consultarse los trabajos: BLÁZQUEZ PANIAGUA, F. (2001), La Teoría Sintética de la evolución en España. Primeros encuentros y desencuentros, Llul, 24, pp. 289-313 y BlÁzQuez PAniaguA, F. (2007), El centenario de El Origen de las Especies en España (1959), eVOLUCIÓN, 2 (2), pp. 33-41.

39 Meléndez, B. (1945), Sintson, G.G. - Tempo and mode in evolution - Columbia University Press; Humphrey, Milford, Oxford University Press, 1944. Boletín de la Universidad de Granada, vol. XVII, pp. 477-478. 
número de individuos de una especies $\mathrm{y}$, finalmente, la selección natural. Remarcaba las soluciones de continuidad existentes en todos los fílum o categorías taxonómicas, afirmando que la «microevolución» y la «macroevolución» de Goldschmidt estaban íntimamente relacionadas, añadiendo además una categoría sistemática más elevada, la «megaevolución». Simpson explicaba las evoluciones, o progresiones «lenta» y «rápida», suponiendo que en el pasado existió adaptación a un ambiente constantemente accesible, es decir, a circunstancias ecológicas que no habían variado fundamentalmente en el transcurso de los tiempos geológicos, o bien que las variaciones se habían producido periódicamente, deduciendo que en estas condiciones todos los cambios eran desfavorables, por lo que tendían a ser eliminados por la selección natural. Definía Simpson la 'ortogénesis' como «inercia en la evolución», no admitiendo que existieran pruebas de que una tendencia determinada en la evolución hubiera seguido su rumbo, aunque fuera frecuente que las ramas filéticas siguieran la tendencia a evolucionar en una determinada dirección durante mucho tiempo.

Meléndez consideraba que esta obra de Simpson era una de las mejor enfocadas y que había sido escrita con gran sinceridad, teniendo en cuenta que abordaba una materia que se prestaba a excesos imaginativos.

Para Simpson, seguía diciendo Meléndez, han existido tres modalidades diferentes en la evolución filogenético:

«1.- Evolución entre especies, «especiación», que nunca traspasa los límites de éstas, por adaptación a subzonas de medio ambiente, que produce la consiguiente ramificación de los extremos de las ramas filéticas.

2.- Evolución filogenética en sentido estricto, que corresponde a un nivel taxonómico medio, dando lugar a nuevas ramas que se separan del tronco común, la cual entraña a menudo en cierto cambio de tendencia en la adaptación.

3.- Evolución en proporción reducida, llamada cuántica por Simpson, caracterizada por rápidas desviaciones de adaptación a un nuevo medio ambiente, que es la que origina los troncos de los nuevos «phylums».» ${ }^{40}$

Terminaba Meléndez su reseña del libro de Simpson, comentando que estaba ilustrado con numerosas figuras intercaladas y que realizaba una discusión y crítica de las teorías de Goldschmidt, J.C. Willis, Schindewolf, etc.

La reseña del libro de Simpson no significó que Meléndez asumiera los planteamientos de Simpson. Por el contrario, en sus trabajos siguientes de 1946 y 1947, el discurso de apertura del curso académico de la Universidad

40 MELÉNDEZ (1945), p. 478. 
de Granada de 1946 a $1947^{41}$, las conferencias pronunciadas los días 6 y 7 de septiembre de 1946 en el VII Curso de Verano de la Universidad de Oviedo ${ }^{42}$ y en capítulo segundo de su Tratado de Paleontología publicado por el CSIC en 194743 , insistía en la necesidad de la intervención de un Agente Superior para explicar el origen de la vida y la aparición de la humanidad y que el transformismo era sólo una hipótesis que habría que corroborar.

En estos trabajos Meléndez comentaba que la aparición de la vida era un tema fundamentalmente metafísico, apelando a una intervención divina para explicar el origen de los primeros seres vivos. En este sentido, consideraba admisible la evolución orgánica, pero siempre en el marco de una concepción animista teísta, guiada por el Sumo Hacedor hacia fines determinados por él y dentro de límites restringidos. Aunque probable, el transformismo era según él aún una hipótesis. En relación a la aparición del género humano, decía que no había eslabones que relacionaran antropomorfos y homínidos, que era imposible que hubiera un paso gradual que salvara el abismo existente entre el psiquismo animal y el humano. El hombre no procedía de ningún mono vivo o fósil conocido, la humanidad no podía ser producto de la evolución orgánica. Era necesario apelar a un acto creador de Dios ${ }^{44}$.

Al discutir sobre la hipótesis transformista, Meléndez ponía al dogma católico como referente. Afirmaba que el transformismo entre animales irracionales y entre vegetales era una cuestión científica y podía ser admitido, mientras que el «transformismo integral», que consideraba a las facultades psíquicas humanas como producto de la evolución natural y espontánea de la materia, era inadmisible. Por último, aceptar un transformismo mitigado que admitiera la creación por Dios de un alma humana y de los principios vitales, no estaba en desacuerdo con el dogma, pero era necesario demostrarlo para ser asumido como cierto.

Con relación al estado actual del transformismo, Meléndez empezaba reconociendo que era admitida por la mayoría de los científicos y que nadie aceptaba la generación espontánea de los organismos. Si al antiguo creacionismo se le podían objetar obstáculos científicos, la existencia de Dios como

41 MelÉndez, B. (1946), Discurso leído en la solemne apertura del curso académico de 1946 a 1947 [Historia de la vida sobre la Tierra], Granada, pp. 9-47.

42 MelÉndeZ, B. (1947a), La hipótesis transformista, Revista de la Universidad de Oviedo, 8 , pp. 5-39.

43 MelÉndez, B. (1947b), Tratado de Paleontología, Madrid, Instituto Lucas Mallada, CSIC, pp. 51-83.

44 MelÉndeZ (1946), pp. 10 y 46-47. 
causa última de la vida en el Universo era innegable, por lo que no podía aceptarse un transformismo absoluto que negara la intervención divina. Así que, dentro del «transformismo teísta», el único que podía admitirse, él postulaba la existencia de dos tendencias, el «generalizado» y el «mitigado». La primera, el «transformismo teísta generalizado», consideraba que Dios sólo había intervenido creando los organismos más rudimentarios en los comienzos de la vida, sin volver a actuar en el resto del proceso evolutivo. La segunda tendencia, el «transformismo teísta mitigado», apelaba a las intervenciones continuas de Dios, tanto en el origen de los primeros organismos como a lo largo del curso de la evolución. Así la intervención divina orientaba la evolución por nuevos caminos y originaba nuevos tipos de organización. La discontinuidad, a manera de cortes, caracterizaba esta explicación, ya que las causas naturales eran por sí solas insuficientes para explicar la aparición de tipos nuevos ${ }^{45}$.

Tras estas publicaciones en las que planteó cuál era su postura frente al evolucionismo, Meléndez discutió en sendos artículos las nuevas tendencias de síntesis neodarwinistas. En el primero de ellos, resultado de una conferencia impartida a finales de octubre de 1947 en la sección de Granada de la Real Sociedad Española de Historia Natural ${ }^{46}$, Meléndez presentaba a la paleontología como la disciplina que más datos ofrecía en contra de la evolución en el mundo orgánico, englobando en este concepto sólo a los animales irracionales y a los vegetales, es decir, excluía al género humano. La nueva tendencia de «síntesis» evolucionista había surgido y desarrollado en los años anteriores y durante la Segunda Guerra Mundial, en los EE. UU. y en Inglaterra. Huxley y Haldane habían liderado esta orientación, en un momento histórico muy propicio para la renovación de viejos cánones científicos, intentando reagrupar a los investigadores de disciplinas como genética, sistemática y paleontología. Había sido esta última ciencia la que, en opinión de Meléndez, había opuesto más resistencia a la nueva teoría de síntesis. Todo había comenzado, según el paleontólogo español, con el paso de T.H. Morgan al campo neodarwinista. Después, la unión entre genéticos y sistemáticos acabó por repercutir en los primeros, quienes comenzaron a utilizar términos darwinistas, como «sistemas de genes» y «poblaciones». Los enfoques matemáticos de Fischer, Haldane y Wright, se hicieron con la intención de volver a la selección natural como agente efectivo de la evolución. Esta tendencia había culminado con la

45 MelÉNDEZ (1947a), p. 10.

46 MelÉNDEZ, B. (1948), La paleontología ante las nuevas tendencias de «síntesis» neodarwinistas, Boletín de la Real Sociedad Española de Historia Natural, XLVI, pp. 143-151. 
obra Genetics and the Origin of Species $(1937,1941)$ de Dobzhansky, en la que éste interpretaba los datos genéticos en términos neodarwinistas. Los sistemáticos, por su parte, estaban aferrados desde antiguo a su tradicional darwinismo, por lo que este movimiento fue acogido sin reservas, como se recogía en las obras de Huxley, The New Systematics (1940), y de Mayr, Systematics and the Origin of Species (1942). Estos dos libros, junto con New Paths in Genetics (1942) de Haldane, podían considerarse como las bases del nuevo neodarwinismo remozado y enriquecido con numerosos datos genéticos. La nueva teoría, seguía diciendo Meléndez, consideraba a la selección natural de Darwin el factor esencial de la evolución, asignándole un papel creador que determinaba cuáles entre las mutaciones debían perpetuarse y qué combinaciones genéticas debían realizarse. Difería del darwinismo clásico porque identificaba las unidades hereditarias. Obviaba cualquier forma de vitalismo, declarándose en consecuencia «antifinalista» y mecanicista. La síntesis evolucionista se había difundido hasta el momento entre los biólogos de los EE. UU. y en Inglaterra, aunque contra ella se había levantado la voz autorizada de Goldschmidt ${ }^{47}$.

Para Meléndez, el problema de la síntesis radicaba en que los estudios realizados sólo comprendían los niveles taxonómicos más bajos y las etapas más pequeñas de la evolución. Este era una importante cuestión para los paleontólogos, acostumbrados a ver la evolución como un fenómeno de mayor amplitud. Decía de Simpson que éste ponía grandes esperanzas en la nueva síntesis, pero pensaba que había muchas posibilidades de que los factores de la evolución que determinaban la especiación trasladados a gran escala acarreasen cambios morfológicos de mayor importancia, sobre todo a lo largo de millones de años, aunque no era probable que los mismos factores provocasen los mismos resultados a gran escala que a pequeña escala ${ }^{48}$.

Según Meléndez, la teoría sintética podría llegar a explicar razonablemente fenómenos de adaptación progresiva y que la evolución fuera gradual, pero nunca que fuera un proceso fundamentalmente orientado en una dirección única, es decir, su carácter finalista. Por eso Meléndez sostenía que la síntesis no era más que un neodarwinismo mecanicista disfrazado y, debido a su «antifinalismo», no era capaz de explicar verdaderamente la evolución. Pensaba que era preciso modificar esta teoría en sus cimientos, incorporando los fundamentos de un vitalismo concebido en términos teístas, ya que «en la Divina Providencia radica la única a no dudarlo, la única razón de ser del mundo

47 MELÉNDEZ (1948), pp. 147-149.

48 MELÉNDEZ (1948), pp. 149-150. 
orgánico y su maravillosa armonía, que el materialismo racionalista contempla con asombro sin ser capaz de explicársela» ${ }^{49}$.

$\mathrm{Al}$ año siguiente Mélendez publicó un artículo parecido, pero con más carga ideológica, en Razón y Fé. Comenzaba diciendo que desde 1935 y durante «nuestra cruzada» y los años de la Guerra Mundial se había desarrollado una tendencia evolucionista, restringida a los EE. UU. y a Inglaterra, que pretendía resucitar la antigua teoría de Darwin renovada con la incorporación de las aportaciones de la genética. Meléndez se mostraba más crítico ya que, al no estar en un ámbito científico como el de la Real Sociedad Española de Historia Natural, podía explayarse en consideraciones ideológicas. Decía que la síntesis surgía con ánimo de redención y de acoger en sus filas a los militantes en antiguas teorías mecanicistas ya desacreditadas. Las noticias un tanto confusas que llegaba de este movimiento científico de la posguerra hablaban de la unificación de genéticos mutacionistas y sistemáticos aferrados al antiguo darwinismo, a los que se intentaban unir, sin gran entusiasmo, los paleontólogos. Volvía a remontar el inicio de la unión a Morgan, un acérrimo detractor del darwinismo que se había convertido en neodarwinista, seguido por otros investigadores en genética, que buscaron en la selección natural, antes combatida por ellos, el agente efectivo de la evolución. En este escenario, los paleontólogos desempeñaban un papel moderador, ya que las leyes empíricas de esta disciplina deducidas de observaciones de fósiles no tenían una explicación lógica en el marco de la nueva teoría evolucionista. Meléndez ponía en guardia a sus lectores para que no se dejaran atrapar por espejismos ni por viejas teorías desacreditadas, aunque aparecieran revestidas de nuevos ropajes $\mathrm{y}$ con el sello de un modernismo mal entendido. Terminaba advirtiendo una vez más que era inútil buscar la respuesta al problema del transformismo fuera de una teoría vitalista teísta, única que poseía la clave de la evolución orgánica, que era la misma que regía los fenómenos vitales, es decir, la Divina Providencia. ${ }^{50}$

El otro gran referente en la paleontología española de los primeros años de la posguerra, que también abordó el tema de la nueva síntesis y el finalismo en la evolución, fue Miquel Crusafont. Estrechamente vinculado al Museo de la Ciudad de Sabadell, Crusafont, licenciado en Farmacia y doctor en Ciencias Naturales, fue colaborador del CSIC en 1951 y catedrático de Paleontología en las universidades de Oviedo y Barcelona en los comienzos de los años sesenta.

49 MELÉNDEZ (1948), pp. 150-151.

50 MÉlendeZ, B. (1949), Las nuevas tendencias de síntesis en el transformismo, Razón y Fé, 139, pp. 70-76. 
La primera publicación donde trató el tema de la evolución fue un trabajo redactado en diciembre de 1947, que leyó cuatro meses después en el laboratorio de Geología de la Universidad de Barcelona, «Concepciones cosmovitalistas del evolucionismo» ${ }^{51}$. Decía que para cualquier paleontólogo era innegable el hecho de la evolución, pero incidía en que este proceso tenía lugar con arreglo a unas normas constantes en determinados sentidos, denominada ortogénesis, que podía ser adaptativa o no. Por tanto, sostenía que la evolución era ortogenética, direccional e irreversible, además de finalista.

En nota a pie de página, Crusafont remitía a la obra de Huxley, Evolution, the Modern Síntesis, de la que decía que había una edición argentina, para tener una perspectiva desde un punto de vista sintético. Se mostraba de acuerdo con Simpson en que existían cinco grandes corrientes en donde podían agruparse las diversas teorías evolucionistas que se habían emitido para explicar las complejas cuestiones que abarcaba el conjunto del proceso de la evolución. Aquí remitía a uno de los personajes que más influyeron en las ideas evolucionistas de Crusafont, Teilhard de Chardin, según el cual se podía hablar incluso de un neoneodarwinismo ${ }^{52}$. Por su parte, Simpson y Crusafont iban a mantener una larga relación epistolar, 195 cartas entre 1942 y $1983^{53}$.

Crusafont declaraba su posición ecléctica, admitiendo a la vez los conceptos mecanicistas y vitalistas de la evolución. Su concepción sobre la evolución la entendía bajo determinados aspectos: 1) La evolución en el sentido vitalista-teísta, que comprendía el origen de la vida, la ortogénesis y la desaparición de grupos de organismos, tres fenómenos que se producían como

51 Crusafont PAiró, M. (1948), Concepciones cosmovitalistas del evolucionismo, Sabadell, Publicaciones del Museo de Sabadell, Sección de Paleontología, fasc. IV. Fue reimpreso posteriormente, con el título «La evolución: un punto de partida» en su obra Evolución y Ascensión, Madrid, Taurus Ediciones, 1960, pp. 15-36.

52 Sobre la influencia de Teilhard de Chardin sobre Crusafont puede verse GLICK, T. (1982), El darwinismo en España en la primera mitad del siglo XX, Anthropos, pp. 1617, octubre 1982, Extraordinario-2. El darwinismo en España en el 1er centenario de la muerte de Ch. Darwin (1882-1982), pp. 76-81 y BlazQuez PANiAguA, F. (2004), Entre Darwin y Teilhard. Notas sobre Paleontología y Evolucionismo en España (1939-1966). En AA.VV., Miscelánea en homenaje a Emiliano Aguirre, vol. II Paleontología, Alcalá de Henares, Museo Arqueológico Regional, pp. 97-107.

53 GLICK, T.H. (1994), Miquel Crusafont i George Gaylord Simpson: interferències biogràfiques, confluències històriques, Arraona, 14, pp. 45-56 y GLICK, T.H. (2008), Miquel Crusafont, Teilhard de Chardin and the Reception of the Synthetic Theory in Spain. En ENGELS, E.M. and Glick, T.H., The Reception of Charles Darwin in Europe, London, New York, Continuum, vol. II, pp. 553-568. 
obedeciendo a una fuerza oculta demiúrgica y 2) Los mecanismos naturales de la evolución, que contemplaba la lenta y prolongada influencia del medio ambiente cuya acción externa prolongada y continua provocaba en un momento dado y bruscamente en el interior de los núcleos de las células, como por un mecanismo de «resorte», la aparición de diversas mutaciones viables. Por último se formaban una serie de formas nuevas, resultado de las mutaciones orientadas por la acción del medio externo. En este punto decía Crusafont que él no renegaba, ni de las ideas lamarckianas de la influencia del medio, con el uso y desuso de los órganos fortificados por la acción sucesiva de las progresivas mutaciones en sentido direccional, ni de las primitivas concepciones darwinistas sobre la selección natural. Aprovechaba aquí para comentar que Haldane rescataba la importancia de este mecanismo y que, como señalaba Piveteau, en la actualidad se asistía en Inglaterra y en América a un renacimiento del darwinismo. ${ }^{54}$

En un trabajo posterior, Crusafont señaló que en el estado actual de las ideas sobre el evolucionismo se podían considerar cuatro escuelas: la «neoneo-darwinista» inglesa (Huxley y Haldane) y norteamericana (Simpson y Colbert), que podía considerarse espiritualistas sólo en el aspecto de una especie de divinización de la vida; la «neo-neolamarckista» soviética (Michurin, Lysenko), materialista y no finalista en ningún sentido; la cientifista francesa, más ponderada y finalista (Caullery, Cuénot, Guyenot, Vialleton, etc.) y la meridional, ecléctica, más darwinista que lamarckista, finalista-teísta (Blanc, Marcozzi, Leonardi, Bugatti-Traverso en Italia, Lecompte du Noüy, Teilhard de Chardin en Francia y Meléndez y Crusafont en España) ${ }^{55}$.

Crusafont, en colaboración con José Fernández de Villalta, organizaría entre 1952 y 1958 cuatro cursillos internacionales de paleontología en el Museo de Sabadell, en los que se discutió sobre el estado del conocimiento sobre la evolución. El enfoque predominante entre los participantes de la escuela meridional fue el finalismo que se desprendía de los datos paleontológicos ${ }^{56}$.

\footnotetext{
54 CRusafont PAiró, M. (1948), pp. 19-24.

55 Crusafont PaIRó, M. (1951), El tema de la evolución orgánica en España, Estudios Geológicos, VII (13), pp. 159-175.

56 Sobre los cursillos internacionales de paleontología de Sabadell puede verse: AGUIRRE, E. (1954), Crónica del II Cursillo Internacional de Paleontología de Sabadell (Barcelona), Ibérica, 20 (295), pp. 457-462; AgUIRRE, E. (1955), Nuevos jalones en el estudio de la evolución. II Cursillo Internacional de Paleontología de Sabadell, Boletín de la Real Sociedad Española de Historia Natural, 53, pp. 149-158; AGUIIRE, E. (1956), Un cambio de impresiones sobre evolucionismo, Estudios Geológicos, XII, pp. 147-161; Coloquio sobre evolucionismo, Cursillos y Conferencias del Instituto Lucas Mallada, Fasc. III, 1956, pp. 147-169; Coloquio
} 
La posición ante la nueva síntesis de los dos autores católicos franceses que Crusafont incluía en la escuela meridional, Pierra Lecompte du Noüy y Teilhard de Chardin, fue objeto de análisis por Joaquín Rojas Fernández. Catedrático de Ciencias Naturales en el Instituto Alfonso VIII de Cuenca, y ex profesor auxiliar de la Facultad de Ciencias de la Universidad de Madrid, Rojas publicó entre el 5 y el 15 de Mayo de 1949 una serie de artículos, bajo el título «Las nuevas síntesis de dos sabios católicos sobre la evolución biológica» en el periódico Ofensiva de Cuenca, órgano de Falange (FET y de la JONS).

Rojas rechazaba la evolución, de la que decía no existían pruebas sólo indicios y sostenía que «el complicado edificio darwinista cimentado en suelos movedizos y levantado sobre estructuras de vigas de madera carcomida, no podía resistir sin desplomarse la severa crítica científica.» A pesar de esto, las teorías materialistas de la evolución, que no precisaban la existencia de un Ser Supremo para nada, estaban tratando de reconstruir el edificio derrumbado. Esto era lo que pretendía las nuevas teorías materialistas, como la nueva síntesis evolucionista comandada por Julian Huxley desarrollada en los Estados Unidos e Inglaterra durante la Segunda Guerra Mundial. Se pretendía con la nueva síntesis unificar los criterios evolucionistas procedentes de la sistemática, de la genética y de la paleontología. Aunque Rojas decía que era una teoría muy bien lograda, afirmaba que su éxito no había sido completo, como reconocían Huxley y Haldane. Para él, era la paleontología la disciplina más combativa contra la nueva síntesis, como sostenía Meléndez.

Rojas citaba la reunión científicas que había tenido lugar en París para intentar conciliar las distintas tendencias evolucionistas y concretar las bases de la evolución. Decía que los distintos especialistas europeos y americanos que habían asistido, como Cuenot, Haldane, Watson, Stensio o Simpson, no se habían puesto de acuerdo sobre los mecanismos de la evolución, aunque sí en el hecho de la misma. En resumen, en su opinión, dos vías opuestas trataban de llegar a la explicación evolucionista: el mecanicismo casualista, vedado a los católicos, y el vitalismo finalista.

Terminaba Rojas planteando las posturas de los católicos ante la evolución, y en concreto de Pierre Lecomte du Noüy y Teilhard de Chardin ante la nueva síntesis. Podía coincidir con ellos en cuestiones como el Human Desti-

sobre el estado actual de la doctrina evolucionista. Cursillos y Conferencias del Instituto Lucas Mallada, Fasc.VI, 1959, pp. 79-92 y TRUYOLS SANTONJA, J. (2004), Los cursillos Internacionales de Paleontología de Sabadell (1952-1958) en el desarrollo de la Paleomastología española. En Miscelánea en homenaje a Emiliano Aguirre, vol. II (Paleontología), Alcalá de Henares, Museo Arqueológico Regional, pp. 617-623. 
$n y$ del primero y la síntesis de la evolución finalista del segundo. Pero se distanciaba de ambos al decir que se sentía más cercano al vitalista von Uexküll y que era posible que el principal factor de la evolución cerebral hubiera sido el cristianismo, al ser el medio que conducía al fin de la evolución.

Asimismo, Andérez, en su trabajo sobre el michurinismo de 1949 antes comentado, y A. Roldán, en su ya citada Evolución de 1950, harán referencia a la nueva tendencia de síntesis en evolución, citando los trabajos de Meléndez, pero sin añadir nada nuevo a lo ya dicho por éste.

Emilio Palafox, biólogo colaborador del Instituto de Investigaciones Zoológicas José de Acosta (Museo de Ciencias Naturales) del CSIC ${ }^{57}$, recogió y comentó en una reseña de Arbor en 1949, tanto los encuentros científicos de París de 1947 y 1948, éste último organizado por el Cercle Rationaliste de La Pensée, y el de Amsterdam de 1948, como el análisis crítico de la teoría sintética de la evolución realizado por Meléndez. Comentaba Palafox que, tras citar las obras de los científicos que habían contribuido a la síntesis moderna, el paleontólogo español coincidía con Goldschmidt en que los genetistas no abordaban los grandes procesos de la macroevolución. Palafox terminaba diciendo que era necesario introducir una interpretación vitalista, finalista y teísta para explicar el desarrollo evolutivo de la vida ${ }^{58}$. A comienzos de la década de los años cincuenta, Palafox publicó dos trabajos, donde discutiría respectivamente, acerca del estado de la cuestión sobre la evolución biológica y de la convergencia hacia la teoría sintética. En el primero de ellos, que formó parte de un monográfico de la revista Arbor sobre el renacimiento del darwinismo y la evolución biológica, Palafox expuso un resumen del estado actual del problema de la evolución biológica, que incluyó referencias a los trabajos de los autores que habían contribuido a la síntesis moderna - Huxley, G.L. Jepsen, Simpson, Mayr - así como de los críticos saltacionistas - Goldschmidt, Schindewolf - y finalistas - Teilhard de Chardin, Lecomte du Noüy, Albert Vandel- ${ }^{59}$. En el segundo artículo, Palafox se centró en la teoría sintética de la evolución. Ofrecía en las conclusiones una visión crítica de la misma, ya que terminaba afirmando que una verdadera síntesis evolucionista debería abarcar tres aspectos. El primero, una base experimental, destacando la muta-

57 En su tesis doctoral (2004), p. 227, notas 222 y 223, Francisco Blázquez Paniagua recoge que Palafox era doctor en Biología, miembro del Opus Dei y que fue ordenado sacerdote.

58 PAlafoX, E. (1949), Tres reuniones científicas en torno a la evolución, Arbor, XII, pp. 390-396.

59 PALAFOX, E. (1951), Sobre la situación actual del problema de la evolución biológica, Arbor, XIX, pp. 185-207. 
ción sistemática de Goldschmidt. El segundo, integraría la investigación del sentido que presidía la evolución progresiva, explicando la aparición progresiva de grupos más desarrollados psíquicamente, como sostenía Vandel, y terminando con el estudio del hombre como sujeto de la evolución. El tercer aspecto sería la síntesis del problema de la evolución y del problema del hombre, integrando la dimensión teológica del hombre en un sistema evolucionista desarrollado sobre bases experimentales ${ }^{60}$.

\section{EPÍLOGO}

La fuerte controversia ideológica en que se planteó la recepción del darwinismo en España en el siglo XIX continuó, durante una gran parte de la primera mitad del siglo XX, con los ataques a Darwin y a la teoría de la evolución, desde una perspectiva de conflicto entre materialismo y creacionismo. Fueron unas décadas con un fuerte ambiente politizado en nuestro país, que culminaron con la rebelión militar y el consiguiente estallido de la contienda civil. Una característica de este período, que abarca desde el eclipse del darwinismo al consenso sobre la teoría sintética, fue el buen nivel de información existente en España sobre las críticas a la selección natural, las teorías evolucionistas alternativas propuestas y los trabajos de los autores que contribuyeron a crear un consenso sobre la teoría sintética de la evolución, como Huxley y Haldane. La modernización de las reformas educativas y los nuevos programas de financiación de pensiones en el extranjero impulsados por la $\mathrm{JAE}$, permitieron incrementar los contactos internacionales con los grupos de investigación líderes en las investigaciones biológicas, así como desarrollar relevantes líneas de trabajo en disciplinas como la genética. Desgraciadamente, esta política científica se vio truncada al terminar la Guerra Civil. Durante la primera década de la posguerra, la síntesis moderna de la evolución fue conocida, comentada y discutida en el área de conocimiento de la paleontología, centrada básicamente en la obra de Simpson. Paleontólogos como Meléndez y Crusafont, asumieron el hecho de la evolución orgánica pero introdujeron matices restrictivos, vitalistas y finalistas. Esta interpretación finalista de la evolución, alternativa a la materialista y mecanicista teoría sintética, se iría moderando con el paso de los años. En paralelo, desde mediados de los años cincuenta, Faustino Cordón, desde fuera de los cauces académicos universitarios, realizó una importante labor de difusión en español de la síntesis

60 Palafox, E. (1952-1953), Hacia una síntesis evolucionista, Theoria, 3-4, pp. 121-127. 
moderna con las traducciones de las obras Genética y el origen de las especies (1955) de T. Dobzhansky y El proceso de toda evolución biológica (1958), compilación de Huxley, A.C. Hardy y E.B. Ford, que incluía un capítulo de Ernst Mayr, otro de los artífices de la síntesis. Pero para que la teoría sintética fuese asumida por la ciencia oficial hubo que esperar hasta bien entrada la segunda mitad del siglo XX. La situación empezaría a cambiar a partir de 1959, como se refleja en las publicaciones y reuniones científicas celebradas para conmemorar ese año el centenario de la publicación de On the Origin of Species de Darwin. Ejemplos de esto último fueron el coloquio sobre la evolución biológica organizado por la Real Sociedad Española de Historia Natural, publicado en el Boletín de la Sociedad dos años después, el Cursillo Internacional de Paleontología de Sabadell, que abordó el estado actual de la doctrina evolucionista, y el monográfico que la Revista de la Universidad de Madrid dedicó a la teoría de la evolución a los cien años de la obra de Darwin. La síntesis moderna de la evolución se iría aceptando paulatinamente en la práctica de trabajo de los biólogos españoles, quienes terminaron incorporando en sus enfoques los principios de la teoría sintética.

Fecha de recepción: 10 de febrero de 2009

Fecha de aceptación: 15 de julio de 2009 